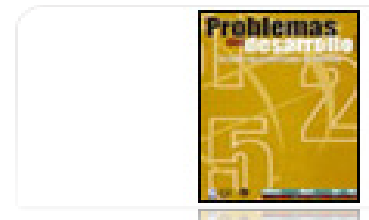

Problemas del Desarrollo. Revista Latinoamericana de Economía

ISSN: 0301-7036

revprode@servidor.unam.mx

Universidad Nacional Autónoma de México

México

Durand, Cédric

Los límites de la inversión extranjera direct (IED) como fuente de ideas para el crecimiento de las economías en desarrollo

Problemas del Desarrollo. Revista Latinoamericana de Economía, vol. 36, núm. 140, 2005, pp. 11-41

Universidad Nacional Autónoma de México

Distrito Federal, México

Disponible en: http://www.redalyc.org/articulo.oa?id=11820092002

- Cómo citar el artículo

- Número completo

- Más información del artículo

Página de la revista en redalyc.org

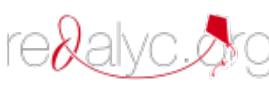

Sistema de Información Científica

Red de Revistas Científicas de América Latina, el Caribe, España y Portugal

Proyecto académico sin fines de lucro, desarrollado bajo la iniciativa de acceso abierto 


\section{LOS LÍMITES DE LA INVERSIÓN EXTRANJERA DIRECTA (IED) COMO FUENTE DE IDEAS PARA EL CRECIMIENTO DE LAS ECONOMÍAS EN

\author{
DESARROLLO
}

\section{Cédric Durand*}

Fecha de recepción: 11 de octubre de 2004. Fecha de aceptación: 4 de febrero de 2005.

\section{Resumen}

El artículo es un estudio conceptual de la relación entre inversión extranjera directa (IED), productividad y crecimiento en las economías en desarrollo. Se discute la afirmación de Romer, según la cual la presencia de las empresas transnacionales permite reducir la brecha de ideas que deja en la pobreza a los países en desarrollo. A partir de una presentación de los mecanismos que permiten una relación virtuosa entre dicha inversión como fuente de ideas, se proponen dos hipótesis. La primera sugiere que existen diferentes condiciones que afectan el efecto neto de la IED sobre la economía receptora y se debe considerar el riesgo de una dinámica perversa. La segunda supone que los determinantes del impacto de la IED son la estructura de la cadena de valor considerada y las configuraciones institucionales en las cuales ocurre la mencionada inversión.

Palabras clave: inversión extranjera directa, productividad, crecimiento, instituciones, cadena de valor.

\section{Abstract}

The article is a conceptual study of the relationship between foreign direct investment (FDI), productivity and growth in the developing economies. We discuss Romer's assertion that the presence of transnational corporations permits a reduction in the ideas gap that leaves developing countries in poverty. From a presentation of the mechanisms that permit a virtuous relationship between investment as a source of ideas, it proposes two hypotheses. The first suggests that different conditions exist to influence the net effect of FDI on the receiving economy where the risk of a perverse dynamic should be considered. The second assumes that the determinants of the impact of FDI are the structure of the value-chain being considered and the institutional configurations in which the investment referred to occurs.

Key terms: foreign direct investment, productivity, growth, institutions, value-chain.

* Posdoctorante en la Facultad de Economía de la unAM, integrante del Centre d'Etudes des Modes d'Industrialisation de l'Ecole des Hautes Etudes en Sciences Sociales (CEMI EHESS), París. Correo electrónico: cdurand@laposte.net 
Résumé

L'article est une étude conceptuelle de la relation entre l'investissement étranger direct (IED), la productivité et la croissance dans les économies en développement. On remet en cause l'affirmation de Romer, selon laquelle la présence des entreprises transnationales permet de réduire la brèche d'idées qui laisse dans la pauvreté les pays en développement. A partir d'une présentation des mécanismes qui permettent une relation vertueuse entre ledit investissement comme source d'idées, deux hypothèses sont proposées. La première suggère qu'il existe différentes conditions qui influent l'effet net de l'IED sur l'économie réceptrice et on doit prendre en considération le risque d'une dynamique perverse. La deuxième suppose que les déterminantes de l'impact de l'IED sont la structure de la chaîne de la valeur considérée et les configurations institutionnelles dans lesquelles a lieu ledit investissement.

Mots clés: investissement étranger direct, productivité, croissance, institutions, chaîne de valeur.

\section{Resumo}

$O$ artigo é um estudo conceitual da relação entre o investimento estrangeiro direto (IED), a produtividad e o crescimento nas economias em desenvolvimento. Discute-se a afirmação de Romer, segundo a qual a presença das empresas transnacionais permite reduzir a brecha de idéias que deixa na pobreza aos países em desenvolvimento. A partir duma apresentação dos mecanismos que permitem uma relação eficaz entre dito investimento como fonte de ideáis, propõem-se duas hipóteses. A primeira sugere que existem diferentes condições que afectam o efeito neto do IED sobre a economia receptora e deve se considerar o! risco duma dinâmica perversa. A segunda supõe que os determinantes do impacto do IED são a estrutura da cadeia de valor considerada e as configurações institucionais nas quais ocorre o mencionado investimento.

Palavras chave: investimento estrangeiro direto, produtividade, crescimento, instituições, cadeia de valor. 


\section{Introducción}

Cuáles son las interdependencias entre inversión extranjera directa (IED), productivi- dad y crecimiento económico en las economías en desarrollo? ¿Cuáles son los obs-

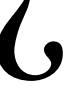
táculos para una relación virtuosa? El propósito de este trabajo es hacer un estudio conceptual de este vínculo. No se abordarán los determinantes de la IED ni se hará una revisión sistemática de los estudios empíricos; sin embargo, se usarán los argumentos propuestos en estos campos de investigación cuando tengan validez y aplicación para nuestro objetivo.

Siguiendo consejos de las agencias multilaterales, desde finales de los años ochenta, la mayoría de los gobiernos de los países en desarrollo han liberalizado la IED y han gastado muchos recursos, en particular en forma de incentivos fiscales y financieros (UNCTAD, 2003a, 1996; Blomström y Kokko, 2003) para atraer a los inversionistas extranjeros. El motivo de esta acción fue la existencia de un consenso, tanto de los ejecutores como en la teoría, para considerar que la IED favorece el crecimiento de los países en desarrollo. Sin embargo, el espectacular incremento de los flujos de IED en la última década no ha logrado corroborar claramente estos efectos positivos sobre el crecimiento y, en el nivel empírico, las investigaciones no son tan contundentes (De Mello, 1997; Dussel Peters et al., 2003; Hanson, 2001; CEPAL, 2004).

La evidencia macroeconómica a escala internacional no puede establecer que la IED ejerza una influencia independiente sobre el crecimiento (Carcovic y Levine, 2002). Además, en los casos que muestran una correlación entre éstos, no se puede establecer claramente si la IED es generadora de crecimiento o si éste es un determinante de la primera, como se supone a menudo (Culem, 1988).

En el nivel meso y microeconómico, muchos estudios empíricos padecen problemas de metodología estadística (Görg y Strobl, 2001). En el mesoeconómico de una industria, la mayoría de los estudios establece un vínculo positivo entre capital extranjero y productividad del sector, en comparación con la economía entera (Blomström y Persson, 1983; Blomström, 1986; Blomström y Wolf, 1989), pero la relación de causalidad entre IED y difusión de la productividad no está clara. En el microeconómico en la manufactura hay resultados contradictorios (Chuang y Lin, 1999; Fuji Olechko, 2004; Smarzynska, 2002; Aitken y Harrison, 1999; Kugler, 2000).

Estas evidencias son muy distintas a las premisas generalmente aceptadas en el nivel teórico, lo cual expresa la necesidad de reanudar un trabajo conceptual acerca del impacto de la IED en las economías en desarrollo.

\section{DeSarrollo}


En este estudio, proponemos explorar dos hipótesis. Una sugiere que no hay automatismo en la relación entre IED y crecimiento. La otra supone que los principales determinantes del impacto de la IED son la estructura de la cadena de valor considerada y las configuraciones institucionales en las cuales ocurre la IED.

En la primera sección expondremos la relación macroeconómica entre IED y crecimiento en los países en desarrollo. En la segunda examinaremos, en el nivel micro y mesoeconómico, los mecanismos de generación de externalidades positivas en presencia de la IED. En la tercera se presentan los diferentes obstáculos para la concresión de esta relación virtuosa, así como los riesgos de generación de dinámica perversa. En las dos últimas secciones veremos de qué manera los factores sectoriales e institucionales influyen en el impacto de la IED.

\section{Relación macroeconómica entre IED y crecimiento}

En el nivel macroeconómico, hay dos mecanismos principales que supuestamente permiten la materialización de un efecto positivo de la IED sobre el crecimiento económico. Por un lado, basado en el modelo Harrod-Domar, se puede suponer que la IED ofrece recursos para financiar el desarrollo. Por otro lado, en el marco de la teoría del crecimiento endógeno, la IED puede ser considerada como una fuente de ideas que, en diferentes niveles, permite incrementar la eficiencia del proceso económico y ampliar el campo de las actividades económicas. Este segundo tipo de influencia positiva es el más discutido en la literatura reciente y el que nos concierne principalmente en este estudio.

\section{La IED como fuente de financiamiento del desarrollo}

La existencia de una relación lineal entre la tasa de ahorro y de inversión de un país y su tasa de crecimiento es una idea derivada del modelo de corto plazo Harrod-Domar (Domar, 1946, 1957).

A pesar de las controversias acerca de la relación entre acumulación y crecimiento (Easterly, 1997; Kuznets, 1963; Collins y Bosworth, 1996), el modelo Harrod-Domar ocupa un lugar central en el pensamiento operativo sobre el desarrollo económico. El método para determinar el monto de la ayuda financiera de las instituciones internacionales a los países pobres se establecía a partir de la existencia de una brecha entre los niveles de ahorro interno y el necesario para permitir el financiamiento del crecimiento económico (financial gap).

Con la crisis de la deuda, la IED fue considerada sustituto de los préstamos públicos para disminuir esa brecha. Pero la contribución de la IED al financiamiento de las economías en desarrollo no es unívoca: la presencia de subsidiarias de las corporaciones transnacionales puede generar un empeoramiento de las cuentas corrientes y de la balanza de pagos resul-

\section{DeSarrollo}


tante de la importación de bienes de capital y productos intermedios, así como de la salida de divisas en forma de repatriación de beneficios, honorarios, pagos de regalías e intereses sobre préstamos privados (Krugman y Obstfeld, 2000; Péres, 1990). Se debe considerar, también, que una parte importante de la IED es financiada con préstamos obtenidos en el país receptor (Delapierre y Milleli, 1995).

Si pareciera que la IED no es una verdadera solución para llenar la brecha de financiamiento en los países en desarrollo, en la literatura especializada se propone otro tipo de mecanismo que permite al país receptor beneficiarse de la presencia de las empresas transnacionales (ET): la IED como fuente de ideas.

\section{La IED como fuente de ideas}

Aunque hace unas décadas que se discute la idea de que las ET puedan contribuir a incrementar el nivel tecnológico de las empresas domésticas en los países en desarrollo (Teece, 1977), desde los años noventa la cuestión es cada vez más central. El problema del desarrollo económico aparece como resultado de una brecha de recursos —al cual se refiere la perspectiva de un déficit de financiamiento - y también de una brecha de ideas (Romer, 1993), no sólo de tecnologías, sino también de conocimientos en términos de gestión, organización, marketing, comunicación, reputación y redes de exportación (Markusen, 1995). En ausencia de costos de oportunidades para este tipo específico de bienes económicos, se considera que la brecha de ideas puede ser bastante sencilla de llenar. "Para los países en desarrollo más pobres, dejar a las empresas transnacionales beneficiarse de la transmisión internacional de ideas es el más rápido y más seguro camino para reducir la brecha de ideas que les deja en la pobreza" (Romer, 1993:548). ${ }^{1}$ En este marco, la presencia de las multinacionales es, en sí misma, un factor positivo para el crecimiento de los países pobres.

Esta concepción del papel positivo de las ET está relacionada con la emergencia de las nuevas teorías del crecimiento económico. En los modelos neoclásicos tradicionales (Solow, 1956), la IED tiene un impacto de corto plazo pero no puede afectar la tasa de crecimiento de largo plazo, que está determinada solamente por el progreso tecnológico y el crecimiento de la población/fuerza de trabajo, ambas variables exógenas. Pero la teoría del crecimiento endógeno (Barro y Sala-i-Martin, 1995; Segerstrom, 1991; Grossman y Helpman, 1991; Romer, 1993, 1994; Ramírez, 2000) abrió la posibilidad de una integración de la IED como término adicional en una función de producción de largo plazo. Se puede considerar este término como un stock de capital, de conocimiento y de tecnología.

En este marco, el impacto positivo de la IED como fuente de ideas para la economía receptora puede ser directo o indirecto. Directamente, la llegada de empresas más eficien-

1 Traducción propia.

\section{Desaarrollo}


tes permite ganancias, como aumento salarial para los trabajadores, precios menores para los consumidores o incremento de recursos fiscales para el Estado (Fuji Olechko, 2004). De manera indirecta, la difusión de tecnologías y de competencias del trabajo desde las empresas extranjeras debe permitir incrementos de la productividad de las nacionales (De Mello, 1997). La IED también puede crear la oportunidad de incorporar nuevas actividades con la integración de nuevos bienes intermedios a la función de producción de los países receptores (Feenstra y Markusen, 1994). Estas externalidades positivas de la IED permiten generar rendimientos crecientes para la economía nacional, incluso si hubiera rendimientos decrecientes en las empresas individuales.

Sin embargo, esta relación entre la IED, la disminución de la brecha de ideas y el crecimiento económico de largo plazo es condicionada por postulados que no siempre son explícitos. El Esquema 1 muestra de qué manera se articulan las cuatro condiciones principales que afectan el impacto de la IED en el crecimiento: la llegada de novedades (novelties), su difusión (spillovers), el efecto de la competencia y la distribución de los eventuales beneficios.

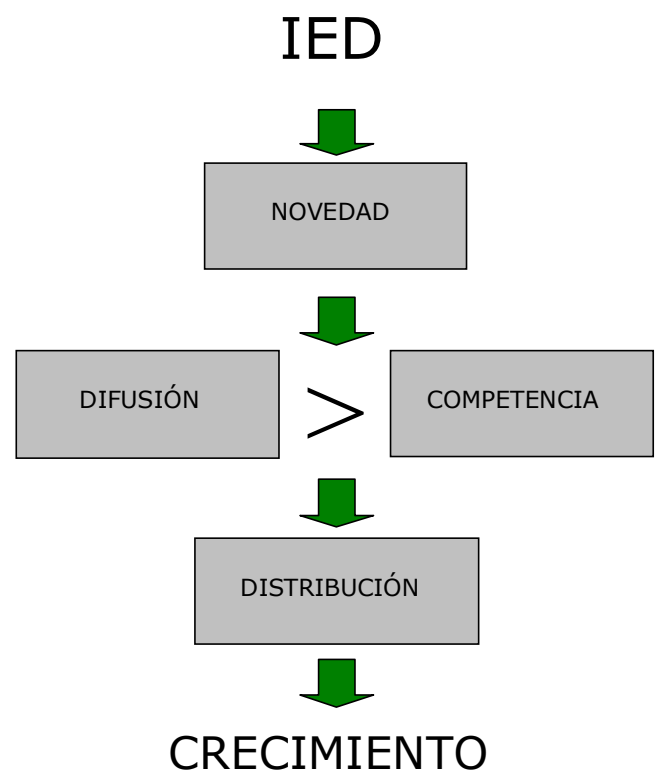

Esquema 1. Condiciones que afectan el impacto de la IED como fuente de ideas.

La condición de novedad está basada en la idea de que el capital extranjero llegue a los países en desarrollo con su competencia y sus ventajas propias, en términos tecnológicos o de gestión. No es una hipótesis trivial; se debe considerar que las empresas con capital extranjero pueden no ser más competitivas que las empresas domésticas, lo que implicaría que el país receptor no recibiera contribución al incremento de su productividad global. 
La evidencia empírica - por ejemplo, las grandes empresas en Venezuela (Aitken y Harrison, 1999) o los joint-venture en Chequia (Djankov y Hoekman, 2000) - muestra situaciones de este tipo.

La condición de difusión sugiere que deben existir mecanismos de difusión de las nuevas ideas a las empresas domésticas, lo cual permite a éstas incrementar su productividad o iniciar nuevas actividades. Entre más constante y efectiva sea la difusión, el impacto positivo podría ser mayor.

La condición de competencia debe ser tal que no se produzca una disminución de la productividad en las empresas domésticas ni dé lugar a un proceso demasiado amplio de destrucción de empresas menos eficientes, en comparación con los beneficios que reporte la difusión de nuevas ideas a las empresas nacionales. De hecho, el cierre de éstas puede generar, al menos en el corto plazo, un efecto depresivo en la actividad económica o una sustitución de la inversión extranjera por la nacional.

Por último, la condición de distribución especifica que las ET pueden tener un proceso productivo más eficiente que las nacionales y reportar a sus proveedores mejoras en la productividad, pese a que se apropiarán totalmente de estas ganancias. En el caso de que proveedores, trabajadores de la ET, clientes o el Estado no se beneficien de los recursos resultantes de la mayor eficiencia del proceso económico, no se puede esperar un incremento de la productividad global y tampoco una aceleración del crecimiento económico en el país receptor.

En conclusión, la relación macroeconómica entre IED y crecimiento económico no es necesariamente positiva. Como fuente de recursos financieros, están en duda los beneficios esperados de la IED, en razón de la salida de flujos relacionados con la presencia de empresas con capital extranjero y de la captación del ahorro interno por las ET. Diferentes condiciones afectan la generación de externalidades positivas de la IED como fuente de ideas. Pero antes de examinar estos obstáculos, hay que precisar los mecanismos que permiten dinámicas virtuosas en los niveles micro y mesoeconómico.

\section{Mecanismos micro y meso de generación de externalidades positivas}

¿Por qué las ET invierten en el extranjero a pesar de los factores que hacen más complicado, costoso y riesgoso operar fuera de su país de origen? La literatura especializada supone que estas empresas tienen ventajas específicas (Hymer, 1976; Caves, 1982; Cantwell, 2000; Wolf, 1977; Kay, 2000; Dunning, 2000) llamadas ideas que, en la perspectiva de Romer (1993), permiten producir algo nuevo o de manera más eficiente que las compañías del país receptor. A partir de la llegada de estas nuevas ideas, la generación de externalidades positivas al resto de la economía receptora puede tomar diferentes canales.

Las nuevas ideas y las ganancias de productividad que éstas permiten pueden difundirse de manera horizontal, es decir, a las empresas de la misma industria. En el marco de las 
relaciones verticales también se pueden generar externalidades positivas en dirección de los proveedores de las empresas transnacionales, hacia atrás (backward linkages), o de sus clientes y de la economía receptora en general, en otras palabras, hacia delante (forward linkages). Más indirectamente, la IED puede impulsar un proceso interindustrial de profundización de la división del trabajo a partir del incremento de la demanda agregada, debido a la difusión de externalidades positivas a las empresas locales.

\section{Difusión de externalidades positivas en las relaciones horizontales}

En el marco de una industria, la difusión de mejoras en la productividad puede realizarse mediante tres fuentes: $a$ ) el incremento de la competencia, lo cual obliga a las empresas domésticas a mejorar costos y calidad de sus procesos productivos; $b$ ) la rotación (turnover) de trabajadores y especialmente de managers, quienes pueden permitir la transmisión del capital humano; $c$ ) la aceleración de la difusión de la tecnología y la imitación de las técnicas de las empresas con capital extranjero por parte de las nacionales (Blomström y Persson, 1983; Blomström y Kokko, 1998). Estos mecanismos son parecidos a los clusters: existen efectos positivos de contaminación de competencias entre empresas de la misma industria (Porter, 1998).

\section{Difusión de externalidades positivas hacia atrás}

En el marco de las relaciones verticales hacia atrás, las mejoras de productividad pueden ser resultado de diferentes mecanismos (Smarzynska, 2002): a) transmisión directa de conocimientos de la empresa extranjera a sus proveedores, por ejemplo, proporcionando asistencia técnica (Moran, 2001); $b$ ) exigencias superiores por parte de las ET, en términos de calidad y tiempo de entrega; $c$ ) transferencias de conocimiento con los movimientos de trabajadores; $d$ ) crecimiento de la competencia en el mercado de productos intermedios con la posibilidad, por parte de las empresas con capital extranjero, de importar los bienes intermedios.

La generación de externalidades positivas hacia atrás también puede ocurrir de manera indirecta. Cuando la llegada de transnacionales y la mejora de la eficiencia del proceso productivo permitan un incremento de la demanda final (doméstica o de exportación) y de los bienes intermedios, los proveedores pueden beneficiarse de rendimientos de escala (Rivera-Bátiz y Rivera-Bátiz, 1990) y aumentar la diversidad de su producción.

\section{Difusión de externalidades positivas hacia adelante}

Este incremento de la demanda también puede contribuir a la generación de externalidades positivas hacia adelante. La disminución de precios, que permite rendimientos de escala, o el incremento de la variedad de bienes intermedios pueden facilitar la entrada de nuevas

\section{DeSarrollo}


empresas de bienes finales y, así, impulsar una dinámica virtuosa y acumulativa de profundización de la difusión del trabajo (Gorg y Strobl, 2001; Markusen y Venables, 1999; Rodríguez-Clare, 1996). Más directamente, se esperan beneficios de la llegada de ET en términos de nuevos bienes o servicios, infraestructura, disminución de costos y aumento de calidad, que contribuyan a un incremento de la competitividad sistémica del país (Mortimore y Vergara, 2003).

Como conclusión de este aspecto, el Esquema 2 propone una presentación sintética de los mecanismos virtuosos de generación de externalidades en la economía receptora de ET y permite mostrar dos dinámicas positivas y complementarias de la IED como fuente de ideas.

Por un lado, se considera que las Eт invierten en el extranjero en razón de sus ventajas específicas/ideas nuevas y de la brecha de idea con el territorio receptor, lo cual ofrece perspectivas de ganancias. Dichas ideas son susceptibles de difundirse a las empresas locales en el marco de relaciones verticales (hacia atrás o hacia delante) y en el nivel intraindustrial. De esta difusión se puede esperar un incremento de la productividad de las compañías locales y, en la economía receptora, rendimientos que permitan una aceleración del crecimiento.

Por otro lado, la difusión de ganancias permite el incremento de la demanda, favorece un mecanismo que profundiza la división del trabajo y crea un efecto de retroacción en favor de la productividad de las empresas locales y de la generación de rendimientos crecientes. Se debe considerar que ese incremento de la demanda - y lo que desencadenase conceptualiza de manera endógena con respecto al mecanismo virtuoso de la IED como fuente de ideas. Sin embargo, este efecto es totalmente dependiente de la existencia y de la difusión de ganancias de productividad en las empresas locales.

\section{Obstáculos a una relación virtuosa y riesgos de dinámica perversa}

Los mecanismos virtuosos no funcionan de manera automática. Hay obstáculos a la generación de externalidades positivas de la IED que se encuentran en los diferentes niveles de las condiciones enumeradas.

En lo que concierne la condición de novedad, no se puede descartar la eventualidad de que las ET inviertan en un país sin llevar nuevas ideas. En el caso de privatizaciones u operaciones de fusión y adquisición, el capital extranjero podría comprar empresas que tienen un poder de mercado local fuerte o que son las más productivas, y solamente capturar sus rentas sin incrementar la productividad.

Sin embargo, si se cumple la condición de novedad, eso no implica mecánicamente que las nuevas ideas vayan a difundirse a las empresas locales. Además, la generación de externalidades positivas para la economía receptora puede ser aniquilada en razón de los efectos destructivos de la competencia o de la concentración de los beneficios obtenidos de las mejoras de productividad en las Eт. Estas dificultades pueden no solamente frenar

\section{Désaarrollo}



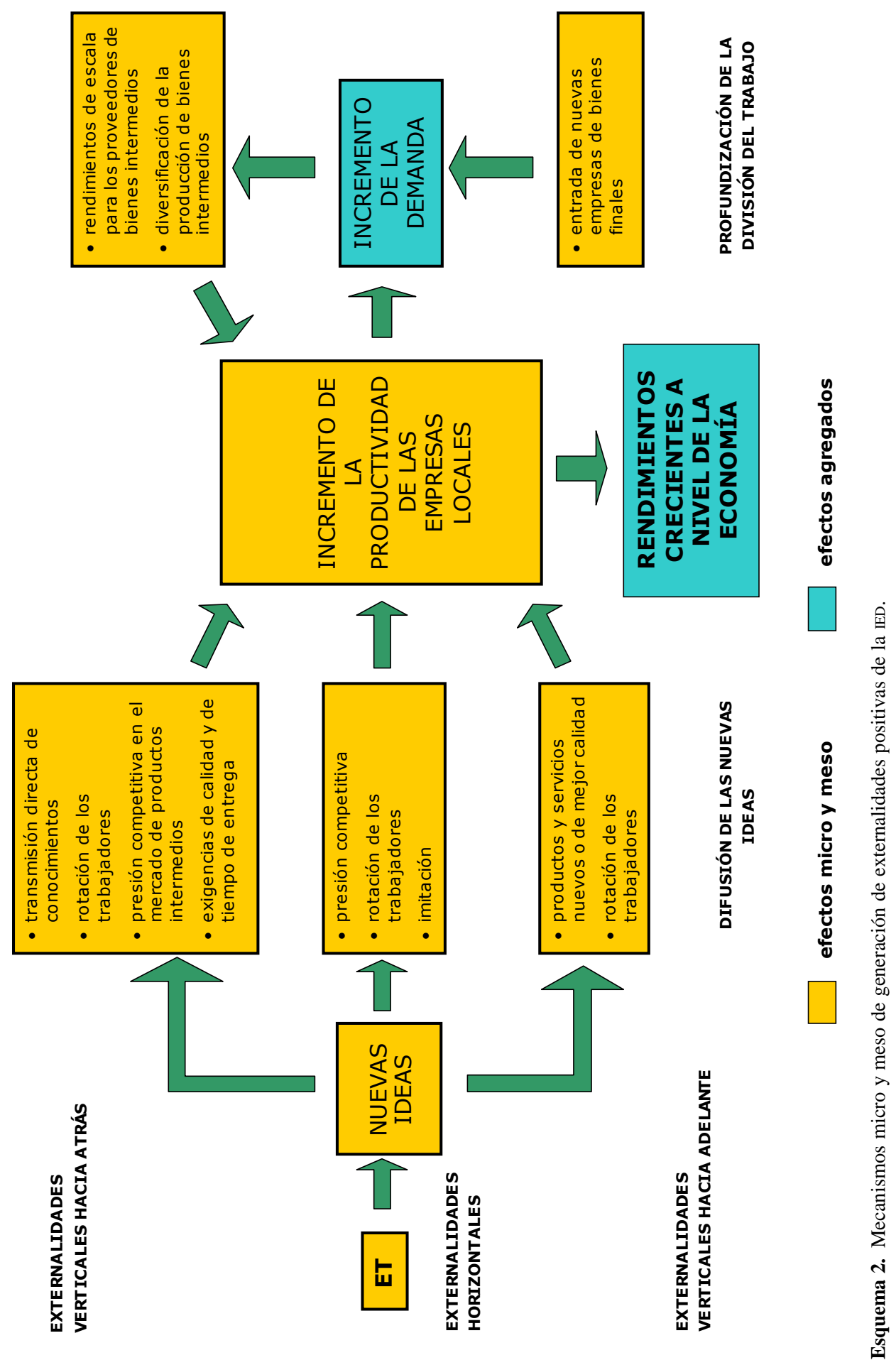

Desaarroullo 
los efectos positivos esperados, sino también alimentar una dinámica perversa de incremento de la brecha de ideas.

\section{Obstáculos a la difusión de ideas}

La forma de la inversión, la brecha entre empresas extranjeras y locales, así como la estructura de las relaciones ET-proveedores son elementos que influyen en las posibilidades de transmisión de nuevas ideas a la economía receptora.

El impacto de la participación local en las unidades que tienen capital extranjero o del tipo de inversión (creación de una nueva unidad, adquisición de una planta) sobre la condición de difusión es discutido en la literatura especializada y parece difícil de determinar. Por un lado, en el caso de que se diera un tipo de acuerdo que incluyera la participación del capital local, las ET temerían la imitación de sus ventajas específicas y, por lo tanto, no integrarían la tecnología y los conocimientos que poseen, lo cual influye negativamente en las posibilidades de difusión (Blomström y Sjölom, 1999). Por otro lado, la propiedad mixta y la inversión extranjera que resulten de una adquisición pueden favorecer la difusión de competencias en función de la preexistencia de relaciones con los proveedores locales (Smarzynska, 2002; UNCTAD, 2001).

El enfoque más frecuente en la literatura es que la amplitud de la brecha tecnológica y de conocimientos entre el territorio receptor y el país de origen de la inversión afectan negativamente las capacidades de las empresas locales para absorber las innovaciones e imitar a los nuevos competidores (Kinoshita, 2000; Rodríguez-Clare, 1996; Kokko, 1994; De Mello, 1997; Djankov y Hoekman, 2000; Xu, 2000; Dussel Peters, 2003; Ruiz Durán, 2004). En este aspecto se presenta una paradoja en lo que concierne al papel de la IED como fuente de ideas para los países en desarrollo: mientras mayor sea la amplitud de la brecha de ideas que el país receptor debe llenar, menores serán sus capacidades para beneficiarse con las externalidades positivas de la presencia de ET.

La debilidad en las posibilidades de imitación por parte de sus potenciales competidores o la ausencia de empresas locales en ese segmento específico de mercado se vuelven factores positivos para la opción de la localización de los inversionistas (Markusen y Venables, 1998). Una vez realizada la inversión, las empresas con capital extranjero van a tratar de impedir o de limitar el proceso de difusión intraindustrial a los competidores nacionales que ya existen o que podrían surgir. Los derechos de propiedad, la integración vertical del proceso productivo o un nivel elevado de salarios son elementos que se pueden implantar para proteger sus rentas (Kugler, 2000).

La brecha entre el territorio receptor y las empresas extranjeras también influye negativamente sobre las posibilidades de aprendizaje en el marco de las relaciones verticales hacia atrás. En particular, la demanda a las empresas locales por parte de las extranjeras

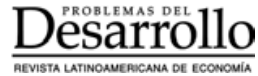


puede estar limitada si las compañías domésticas no cuentan con la capacidad de satisfacer los requerimientos de las ET.

Para la generación de externalidades positivas en el marco de relaciones hacia atrás, una buena estructura de circulación de la información y la existencia de garantías en lo que concierne al uso de esta información son elementos muy importantes (Aoki, 1988). Se puede hacer una distinción entre subcontratación de corto plazo, subcontratación vertical y subcontratación sistémica o dinámica (Dussel Peters, 1999) y mostrar que hay más posibilidades de aprendizaje en este último marco, caracterizado por una relación contratistaproveedor, en el largo plazo de corte semihorizontal, en el cual los costos son compartidos y se minimiza la incertidumbre de ambas empresas. Por el contrario, si la relación de subcontratación es de subordinación o de corto plazo, las posibilidades de aprendizaje serán más limitadas.

\section{Efectos negativos de la competencia en las empresas locales}

Si el aumento de la competencia puede imponer a las empresas locales un incremento de su productividad, la llegada de consorcios extranjeros más efectivos puede reducirla.

Con sus competencias propias, las Eт pueden quitar cuotas de mercado a las nacionales, confinarlas en los segmentos de menor rentabilidad (Hanson, 2001) o eliminarlas. Esta dinámica de marginación implica una eficiencia menor del proceso productivo de las empresas locales en razón del mantenimiento de los costos constantes. En el nivel sectorial, esta evolución puede aniquilar el incremento de la productividad relacionado con la entrada del capital extranjero (Aitken y Harrison, 1999; Djankov y Hoekman, 2000) o implicar una pérdida de competencias locales, aunque se trate de empresas menos efectivas que las ET. Además, éstas pueden financiar una política de precios muy bajos, con pérdidas temporales, para ganar cuotas de mercado y tratar de eliminar competidores (Kugler, 2000).

En el marco de las relaciones verticales hacia atrás, la llegada de ET con sus proveedores extranjeros habituales también puede producir este mecanismo perverso si éstos quitan clientes tradicionales a los proveedores locales.

\section{Concentración de los beneficios del incremento de la productividad}

La llegada de empresas extranjeras puede conducir a un incremento de la eficiencia del proceso productivo del sector donde actúan o de los segmentos proveedores pero, al mismo tiempo, pueden acaparar gran parte o la totalidad de los beneficios (Smarzynska, 2002; Blomström y Kokko, 1998). Cuando éstos no se redistribuyen a las empresas, trabajadores y consumidores locales o se pagan en forma de impuestos, no habrá incremento de la productividad en la economía receptora.

En los países en desarrollo, el capital extranjero suele escoger las actividades y los contextos en los cuales no existe fuerte competencia. En razón de la correlación entre

\section{DeSarrollo}


grado de concentración de un nodo de las cadenas globales de valor y parte del valor agregado global de la cadena que se puede concentrar dentro de dicho nodo (Hopkins y Wallerstein, 1994), las ET pueden beneficiarse de rentas, que son resultado de una combinación de productividad diferenciada de factores y barreras a la entrada (Kaplinsky 2000) que permita aprovechar posiciones de poder en el mercado. La evidencia empírica confirma esa correlación entre un grado elevado de concentración y capital extranjero (Morán, 2000), lo cual sugiere una fuerte posibilidad de que las empresas con capital foráneo se beneficien de rentas de monopolio, de monopsonio o de oligopolio (UNCTAD, 2001) a costa de la productividad global de la economía receptora.

Más específicamente, en el marco de las relaciones con los proveedores, el vínculo de poder dentro de las redes productivas organizadas alrededor de las ET tiene implicaciones distributivas (Sacchetti y Sudgen, 2003). La opción de la subcontratación puede responder a la voluntad de las compañías con capital extranjero de utilizar empresas totalmente dependientes para obtener, por un lado, más flexibilidad en la gestión de variaciones de la actividad y, por otro lado, un trabajo más barato y menos sindicalizado (UNCTAD, 2001; Asad y Balakrishnan, 2002), conforme con el principio "divídase y gobierne" (divide and rule) (Bowles, 1985). Como las ET son actores que juegan a escala global, este tipo de mecanismos puede inscribirse en una "carrera hacia abajo" (race to the bottom): los productores locales siempre deben disminuir sus costos para conservar sus contractos con las ET, lo cual puede inducir una dinámica de "crecimiento empobrecedor" (immiserising growth), en la cual el incremento de la actividad se realice en el marco de rendimientos decrecientes (Kaplinsky, 2000).

El Esquema 3 propone una síntesis de los principales puntos que la literatura especializada trata acerca de los obstáculos que impiden la generación de externalidades positivas de la IED como fuente de ideas.

En primer lugar, se encuentran trabas en la fuente del proceso que impiden la difusión o la absorción de las ideas en las empresas locales. Estos escollos son, principalmente, la amplitud de la brecha de desarrollo entre el territorio receptor y el país de origen, la ausencia o la eliminación de proveedores o competidores locales, las estructuras asimétricas de información que limitan la generación de externalidades en las relaciones con los proveedores, así como las herramientas de retención de ideas que pueden usar las ET.

En segundo lugar, hay barreras indirectas. El incremento de la competencia puede conducir a una marginación de las empresas locales del sector y disminuir su productividad. Por otra parte, las ET pueden apropiarse totalmente las ganancias de productividad que contribuyen a difundir en la economía receptora (véase Esquema 3).

Como se puede observar en el Esquema 4, la llegada de nuevas ideas y la presión competitiva que generan las ET son elementos que pueden conducir a una dinámica perversa: además de excluir las posibilidades de difusión horizontal, la ausencia o la eliminación

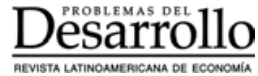




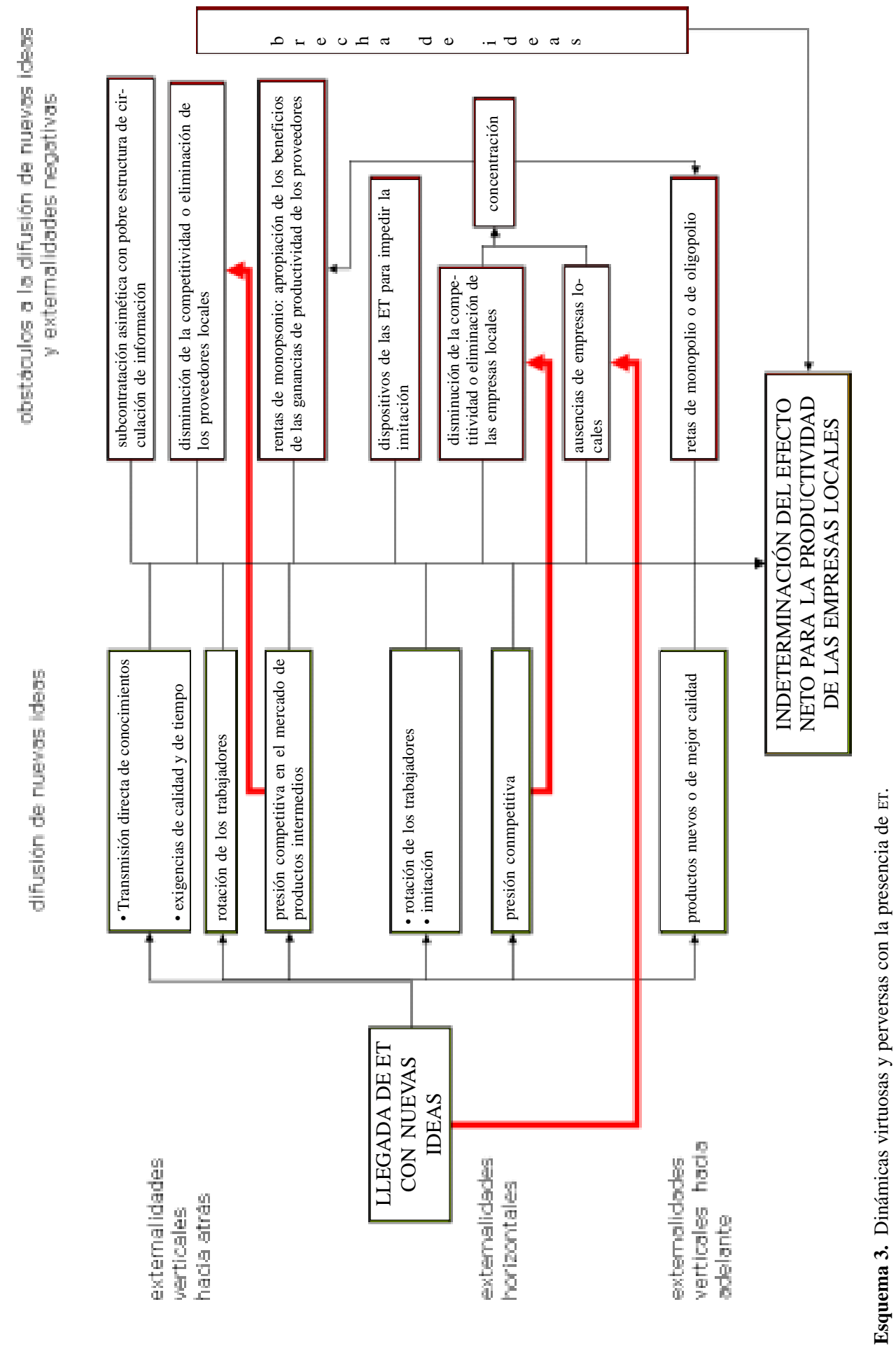




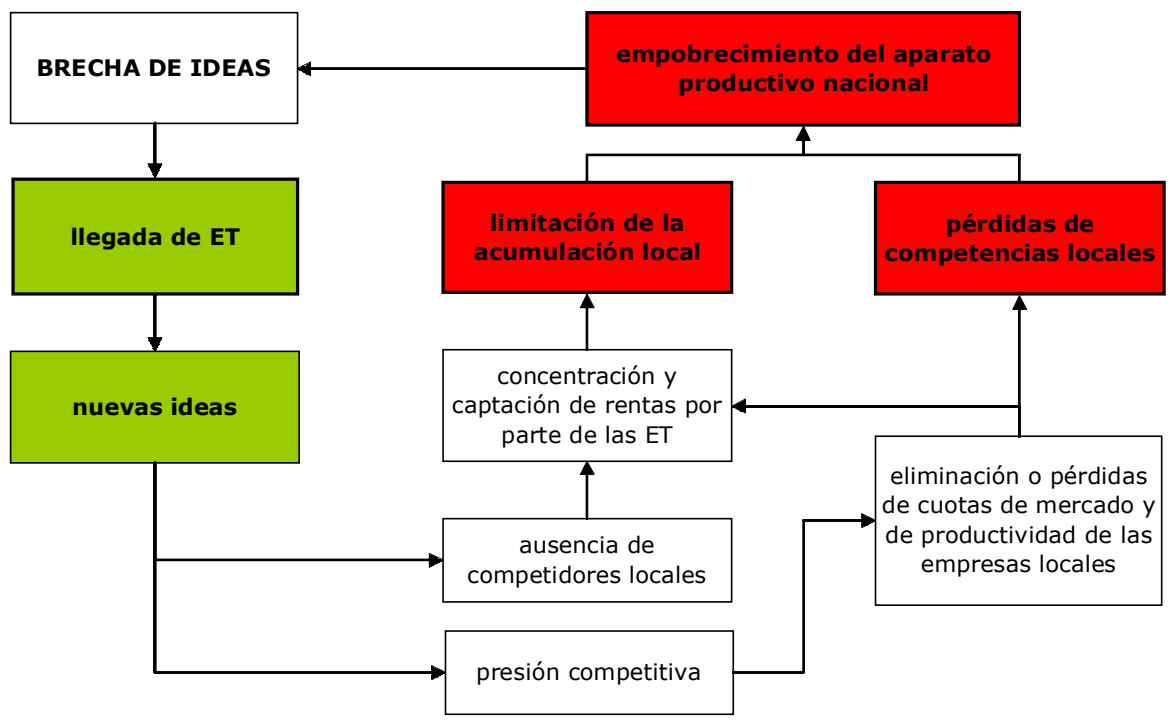

Esquema 4. Dinámica perversa de incremento acumulativo de la brecha de ideas.

de los competidores locales implica una concentración de la actividad y favorece la captación de rentas en el marco de las relaciones verticales de las ET.

De este modo, con la exclusión del aparato productivo local de algunos sectores, se inicia una profundización de la brecha de ideas, es decir, pérdida de competencias y limitación del proceso de acumulación en las empresas locales.

El examen de los mecanismos de generación de externalidades positivas de la IED como fuente de ideas, así como de los obstáculos y de los riesgos de dinámicas perversas, no permite establecer claramente si la presencia de las ET tiene un efecto positivo o negativo sobre la economía receptora. Para superar esta indeterminación, hay que identificar los elementos que afectan dichos mecanismos relacionados con la llegada de ET.

\section{Impacto de las configuraciones sectoriales en las externalidades de la IED}

Una fuerte carencia en la literatura sobre el tema es que los autores se enfocan principalmente en el impacto de la IED en el sector manufacturero (Mortimore y Vergara, 2003). Esta prioridad no puede considerarse como una aproximación de lo que sucederá con la IED en general (véase Figura 1): la manufactura representa solamente 33\% de la IED en los países en desarrollo, cuando el sector de los servicios representa 58\%.

Una explicación de la falta de atención de la literatura hacia los servicios puede ser que la mayor parte de la IED en este sector - con excepción del transporte y las comunicaciones- se encuentra en actividades en las cuales no existe una metodología ampliamente 


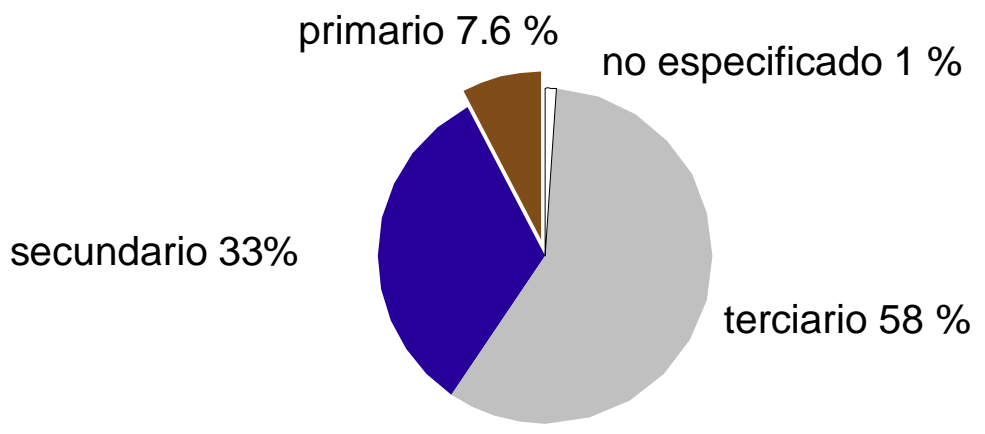

Figura 1. IED por sector en los países en desarrollo en 2001 (UNCTAD, 2003a).

aceptada para medir la productividad (Petit, 2003; Griliches, 1994), lo que impide un trabajo empírico como el referido a la manufactura. Esta distorsión en la teoría parece ser un gran problema en razón de la fuerte heterogeneidad de las posibilidades de generación de externalidades positivas de la IED según las configuraciones sectoriales.

Para examinar estas diferencias, la presentación de configuraciones ideales-típicas por sector, según las estrategias de las ET, permite ofrecer una aproximación.

\section{Las ET en la manufactura}

La llegada de las ET que buscan mercado en la manufactura es la configuración más considerada en la literatura especializada. Todos los canales de difusión (horizontal, vertical hacia atrás, vertical hacia adelante) de mejoras de productividad son potencialmente activos. Sin embargo, pueden intervenir los obstáculos y dinámicas perversas ya identificados.

La estrategia de búsqueda de eficiencia de las ET en la manufactura abre menores posibilidades de externalidades positivas. La difusión de ideas no puede ocurrir en el marco de las relaciones hacia adelante - con la excepción de potenciales efectos indirectos logrados con la rotación de los trabajadores- porque su producción está destinada a la exportación. En el nivel vertical hacia atrás, la generación de externalidades positivas también tiene poca probabilidad. Debido a las diferencias de estándares y de costumbres de consumo, hay más probabilidades de que las filiales de las ET que trabajan para el mercado local compren sus inputs en este ámbito, mientras que las exportadoras importan bienes intermedios o favorecen a proveedores extranjeros (UNCTAD, 2001; Smarzynska, 2002; Blomström y Sjölom, 1999).

Otro problema es que los segmentos de la cadena productiva global (Gereffi y Korzeniewicz, 1994) ubicados en los países en desarrollo, ante esta estrategia responden muchas veces a procesos bastante rudimentarios. Además, las empresas locales generalmente no están en capacidad de competir con las ET debido a las barreras que impiden el acceso autónomo a los mercados de exportación o el upgrading a funciones de diseño de 
los productos (Kaplinsky, 2000; Humphrey y Schmitz, 2001; Schmitz y Knorringa, 1999). Este tipo de obstáculo también puede ocurrir cuando las ET buscan acceso al mercado en un sector en el cual no existen empresas locales con capacidad de competir.

Finalmente, hay que considerar que, a diferencia de lo que ocurre en los países desarrollados, la participación del capital extranjero en clusters en los países en desarrollo se restringe, principalmente, a situaciones en las cuales las ET que siguen estrategias de búsqueda de eficiencia se benefician entre sí mismas de las externalidades positivas de la especialización territorial. Es, por ejemplo, lo que se puede observar en Jalisco, México, donde las ET que dominan la industria electrónica han ubicado una parte rudimentaria de la cadena de valor global con bajo grado de endogeneidad territorial (Dussel Peters, 2003). No solamente no hay posibilidades de difusión intraindustrial por la ausencia de empresas locales, sino que además las oportunidades de difusión vertical son muy débiles porque el dominio de un modelo de importaciones temporales para su reexportación excluye a los proveedores locales.

\section{Las ET en los servicios}

La IED en el sector de los servicios fue inicialmente limitada a estrategias de búsqueda de mercado en los servicios financieros y de negocios pero, durante la última década, se ha incrementado espectacularmente la presencia de las ET en electricidad, telecomunicaciones y distribución comercial. Se debe considerar que, en años recientes, con la disminución de los costos de comunicación, algunas ET empezaron a dividir el proceso de producción y a localizar componentes de las cadenas de valor en países con salarios más bajos. Estas estrategias de búsqueda de eficiencia se aplican en actividades como los centros de llamada (call centers), el tratamiento de datos y el desarrollo de software. Se supone que este proceso de reorganización global de las cadenas productivas de los servicios va a ampliarse fuertemente (UNCTAD, 2003 b).

En términos generales, parece que las posibilidades de difusión vertical hacia atrás de innovación son mucho más reducidas en los servicios que en la manufactura, en función de la dificultad de dividir el proceso productivo entre diferentes empresas. Cuando existen relaciones de subcontratación, por ejemplo, en el turismo, suele ser de manera muy asimétrica para beneficiarse de costos de trabajo más bajos, razón por la cual se espera poca transferencia de competencias (UNCTAD, 2001).

Las actividades de las ET que siguen una estrategia de búsqueda de eficiencia son orientadas a la exportación y casi totalmente desligadas de las actividades económicas del país receptor. En esta configuración, difundir externalidades verticales parece solamente posible con los movimientos de trabajadores calificados.

La difusión horizontal de externalidades positivas puede cumplirse en los mismos canales que en la manufactura. La literatura sobre la IED en el sector financiero sugiere que 
el incremento de la competencia es el principal factor que explica el incremento de la eficiencia en el nivel horizontal (Goldberg, 2004). Sin embargo, en los casos de la IED relacionada con estrategias de búsqueda de mercado en un contexto de privatización, muchas veces no se pueden esperar efectos de difusión horizontal si se observa la formación de monopolios privados en lugar de los antiguos monopolios públicos (UNCTAD, 2003b). Es lo que ocurre con las ET que siguen estrategias de eficiencia o que introducen una nueva actividad.

Es en el marco de las relaciones verticales hacia adelante, con la presencia de ET que siguen una estrategia de búsqueda de mercado, donde se esperan mayores beneficios. Nuevos servicios o infraestructuras, disminución de costos o aumentos de calidad podrían favorecer la competitividad sistémica del país con un incremento de la productividad global de la economía (Mortimore y Vergara, 2003). Cuando la llegada de las ET se da en el marco de una privatización, se esperan beneficios de la experiencia internacional y de las competencias de las ET, así como de la eliminación de la supuesta ineficiencia de la propiedad pública (Ambrose, Hennemeyer y Chapon, 1990; unCTAD, 2003b; Bellier y Zhou, 2003).

Sin embargo, hay un riesgo de que se formen monopolios u oligopolios extranjeros que maximicen sus rentas sin necesidad de incrementar la calidad ni diversificar la oferta de servicios. Hay muchos ejemplos que sugieren la necesitad de tomar este riesgo en consideración. En Argentina, las empresas transnacionales que llegaron con la privatización de servicios financieros o de distribución han seguido un comportamiento predatorio, tanto antes como después de la crisis (CEPAL, 2002). En Brasil, el incremento de la inversión con las privatizaciones en la industria eléctrica no sólo no se cumplió, sino que se produjo una abrupta disminución de la inversión en el sector. Para evitar un colapso, el Estado brasileño se encargó del rescate financiero de las filiales de las grandes corporaciones transnacionales (CEPAL, 2004).

Otro ejemplo es que, con la llegada de los bancos extranjeros a América Latina, no ha habido incremento de la eficiencia del servicio; al contrario, se observa escasez del crédito (CEPAL, 2003) y, a veces, un aumento del costo de los servicios. ${ }^{2}$

Existe un problema de metodología. La distinción entre el incremento de la eficiencia de las empresas en términos de resultados financieros, por un lado y, por otro, el incremento de la calidad o la disminución de los precios de los servicios no es clara (Goldberg, 2004). Así, se verifica una correlación entre privatizaciones e incremento de la tasa de ganancias, sin embargo, se encuentran pocas evidencias acerca de cómo se ven afectados los consumidores (Megginson y Netter, 2001).

2 Las declaraciones del gobernador del Banco de México, Guillermo Ortiz Martínez, ante la Comisión de Hacienda y Crédito Público del Senado de la República el 31 de marzo 2004 dan fe de este problema. Las tarifas y comisiones bancarias se encuentran en la página del Banco de México: http://www.banxico.org. $\mathrm{mx} /$ SistPagos/homespext.html

\section{DeSarrollo}




\section{Las ET que siguen una estrategia de búsqueda de recursos naturales}

La generación de externalidades positivas con la llegada de empresas que siguen una estrategia de búsqueda de recursos naturales es muy improbable (por ejemplo, véase el caso de la IED en el sector del gas en Trinidad y Tobago, en Barclay, 2003). De hecho, el principal efecto que se espera de este tipo de IED es el incremento de los flujos de exportación (Mortimore, 2000), en razón del incremento de la inversión en la búsqueda de los yacimientos y en la explotación de las reservas.

En el nivel horizontal, la expectativa de difusión es casi inexistente porque muchas veces las inversiones son resultado de la ausencia de empresas locales del mismo tipo o de la privatización de las empresas públicas. Además, se debe considerar que los determinantes de la productividad de las empresas en este sector (condiciones naturales de explotación, formas de los contratos y maquinaria pesada) son difícilmente transferibles.

En el nivel vertical, la posibilidad de difusión hacia atrás es muy reducida, por las pocas relaciones con proveedores locales (UNTCAD, 2001), y hacia adelante se espera que el principal beneficio de la llegada de las ET sea un incremento de los recursos fiscales. No obstante, el problema de distribución de la renta generada por la explotación de los recursos naturales implica una posible relación de conflicto entre el Estado receptor y la ET (Sweezy y Magdoff, 1974; como ejemplo reciente, véase la cuestión del gas en Bolivia: CEPAL, 2004; Intermón Oxfam, 2004).

El Cuadro 1 propone una síntesis heurística del grado más o menos posible de generación de externalidades positivas de la IED según los sectores, las estrategias de las ET y la dirección de las relaciones.

Hemos dado a cada una de las configuraciones una nota $(0,1 \mathrm{o} 2)$, en función del grado de posibilidad de difusión. El valor $O$ corresponde a situaciones en las cuales no hay canales de transmisión de ideas, fundamentalmente debido a la ausencia de un marco de

Cuadro 1

Grado de posibilidad de externalidades positivas de la IED según las estrategias de las ET, el sector y la dirección de difusión

\begin{tabular}{lcccc}
\hline \multicolumn{1}{c}{$\begin{array}{c}\text { Dirección de difusión } \\
\text { Estrategias }\end{array}$} & Horizontal & $\begin{array}{c}\text { Vertical } \\
\text { hacia atrás }\end{array}$ & $\begin{array}{c}\text { Vertical } \\
\text { hacia adelante }\end{array}$ & Total \\
\hline Búsqueda de mercado en la manufactura & 1 & 2 & 2 & 5 \\
Búsqueda de eficiencia en la manufactura & 1 & 1 & 0 & 2 \\
$\begin{array}{l}\text { Búsqueda de mercado de servicios } \\
\text { Búsqueda de eficiencia en los servicios }\end{array}$ & 1 & 0 & 2 & 3 \\
Búsqueda de recursos naturales & 0 & 0 & 0 & 0 \\
\hline \multicolumn{2}{c}{ Total } & 3 & 3 & 5 \\
\hline Grado de posibilidad 0 : casi inexistente & 1: débil & 2: regular &
\end{tabular}


interacción (vertical-cooperativo u horizontal-competitivo) con empresas locales. Sin embargo, no excluye la posibilidad de difusión de competencias con la rotación de trabajadores. El valor 1 corresponde a situaciones en las cuales hay pocas esperanzas de que exista un marco de interacción con las empresas locales que pueda permitir la transmisión de ideas o que se espere el desarrollo de efectos negativos. El valor 2 corresponde a situaciones en las cuales puede haber un marco de interacción entre la empresa extranjera y las locales. Esta evaluación no presenta una apreciación sistemática según las configuraciones de obstáculos, en consecuencia, ni el valor 2 significa un comportamiento automático en la generación de externalidades positivas: siempre pueden surgir obstáculos o las externalidades negativas que impidan o superen a las positivas.

Con la presencia en el sector de la manufactura de ET que buscan acceso al mercado hay mayores posibilidades de generación de externalidades positivas porque suponen la activación potencial de todos los canales de difusión de conocimientos. Sin embargo, dichas posibilidades parecen menos consistentes en el marco intraindustrial, no solamente por la amplitud de la brecha — que es uno de los principales motivos de la llegada de las ET-, sino también por los esfuerzos de las ET para impedir la transferencia de competencias a sus rivales, así como por los efectos destructores de la pugna.

En el caso de las ET que buscan eficiencia en la manufactura, parece poco posible que se generen externalidades en función de la probable ausencia de empresas locales tanto en el nivel de los proveedores como de los competidores, pero también por el carácter, a menudo rudimentario, de los procesos involucrados. Debido a la orientación hacia la exportación, casi no hay difusión hacia adelante.

En el caso de las ET de servicios que buscan mercado, se espera la difusión en el marco de las relaciones hacia adelante y, por los mismos motivos que en la manufactura, ésta se producirá de manera menos importante en el nivel horizontal.

Las ET que buscan eficiencia en los servicios apenas tienen posibilidades de difusión por la debilidad de sus relaciones con los proveedores locales, mientras que en las que buscan recursos naturales, la difusión de beneficios hacia adelante solamente puede provenir del incremento de los recursos fiscales.

En lo que concierne a los canales de difusión, es en el marco de las relaciones verticales hacia adelante que parece más posible la generación de externalidades, cuando las ET buscan acceso al mercado. En el marco de las relaciones horizontales, las posibilidades parecen más débiles en todos los casos, en razón tanto de los obstáculos a la difusión como de las externalidades negativas de la presencia de las Eт. Hacia atrás, las posibilidades de difusión se limitan a la influencias en el sector manufacturero y, sobre todo, a las ET que buscan mercado.

\section{DeSarrollo}




\section{Influencia de las instituciones sobre el impacto de la IED}

Las posibilidades de generación de externalidades positivas de la IED, así como la distribución de los obstáculos, no son uniformes según las actividades consideradas. Sin embargo, el marco institucional influye en dichas externalidades. Después de una presentación muy sintética de algunos conceptos clave para el análisis institucional del crecimiento, examinaremos las herramientas institucionales que pueden ser usadas por las instancias de gobernanza (governance) de los países en desarrollo para influir sobre el impacto de la IED y cuáles son sus limitaciones.

\section{Instituciones, sistemas sociales de producción y gobernanza}

Según la definición canónica de North, las instituciones pueden considerarse como las reglas del juego (moneda, derechos de propiedad, por mencionar algunos) en oposición a organizaciones y personas, que son jugadores (North, 1990, 1993). Estas reglas formales e informales dan lugar a las regularidades que permiten interactuar a las partes involucradas, a pesar de la incertidumbre radical y su racionalidad limitada (Commons, 1934; Dugger, 1989; Durkheim, 1893; Sapir, 2000). Son la cristalización de relaciones sociales conflictivas (Aglietta, 1982) y pueden ser vistas como un stock resultante de las políticas pasadas (Rodrick, Subramanian y Trebbi, 2002) pero, más generalmente, de un proceso intencional e inintencional de organización de la sociedad (Menger, 1883; Rutherford, 1994; Vanberg, 1994).

Es ahora ampliamente aceptado que las dinámicas económicas son, en gran medida, determinadas por sus aparatos institucionales. Los trabajos sobre trayectorias tecnológicas (Piore, 1991), competitividad sistémica (Esser, Hillebrand, Messner y Meyer-Stamer, 1997; Dussel Peters, 2003) y las perspectivas de los sistemas sociales de producción (Hollingsworth y Boyer, 1997; Amable y Petit, 1999) tratan de analizar las configuraciones institucionales y su interacción con los procesos de producción y de crecimiento, lo cual implica enfrentarse con diferentes niveles de complejidad:

- Las instituciones son complementarias de otras instituciones, así como no existe un one best way para todos los territorios y todos los momentos;

- Los diferentes sectores, según sus características y sus regímenes de producción (flexible en masa, especialización flexible, fordista, entre otras), no necesitan las mismas configuraciones institucionales para coordinarse;

- Las configuraciones institucionales deben ser consideradas como articulaciones de reglas de diferentes niveles, desde el local hasta el global.

La noción de gobernanza (governance) se refiere a la parte deliberativa de la generación de instituciones, instrumentos de definición y de cambio intencional de las reglas del

\section{Désaarrollo}


Cuadro 2

Instancias públicas, privadas o mixtas de gobernanza en los niveles local, nacional y supranacional

\begin{tabular}{|c|c|c|c|}
\hline & Nivel local & Nivel nacional & Nivel supranacional \\
\hline Gobernanza privada & $\begin{array}{r}\text { - Asociaciones } \\
\text { empresariales }\end{array}$ & $\begin{array}{r}\text { - Asociaciones } \\
\text { empresariales }\end{array}$ & $\begin{array}{l}\text { - Cadenas de valor global } \\
\text { - Asociaciones empresariales }\end{array}$ \\
\hline Gobernanza pública & $\begin{array}{l}\text { - Gobiernos locales } \\
\text { y regionales }\end{array}$ & $\begin{array}{l}\text { - Estado nacional } \\
\text { e internacionales }\end{array}$ & - Organizaciones regionales \\
\hline $\begin{array}{l}\text { Gobernanza } \\
\text { pública-privada }\end{array}$ & $\begin{array}{l}\text { - Redes políticas } \\
\text { locales y regionales } \\
\text { - Movimientos } \\
\quad \text { sociales }\end{array}$ & $\begin{array}{l}\text { - Redes políticas } \\
\text { nacionales } \\
\text { - Organismos paritarios } \\
\text { - Movimientos sociales }\end{array}$ & $\begin{array}{l}\text { - Redes políticas internacionales } \\
\text { - Estandartes internacionales } \\
\text { - Campañas internacionales } \\
\text { de ong y de movimientos } \\
\text { sociales }\end{array}$ \\
\hline
\end{tabular}

juego. Sin entrar en debate acerca de la importancia relativa de los diferentes niveles de gobernanza, el Cuadro 2 (transformado desde Humphrey y Schmitz, 2001) muestra, de manera simplificada, cuáles son las principales instancias de gobernanza — públicas, privadas o mixtas - que intervienen en los niveles local, nacional y supranacional (regional y global) para definir las instituciones.

El consenso creciente con respecto de la importancia del análisis institucional para entender los mecanismos de crecimiento tiene implicaciones para la comprensión de los procesos de generación de externalidades de la IED. En esta sección solamente trataremos de esclarecer brevemente un aspecto del problema: cómo las instancias deliberativas locales y globales pueden interferir en dicha generación de externalidades de la IED. Más precisamente, mostraremos las posibilidades de acción de las instancias de gobernanza locales y nacionales, así como sus limitantes. Existen dos tipos principales de intervención para influir en el impacto de la IED: incrementar las capacidades de apropiación de las ideas por parte de las empresas locales y seleccionar la IED o poner condiciones para la llegada de las ET para limitar, así, los obstáculos a la difusión de ideas y los riesgos de dinámicas perversas.

\section{Promover la difusión de ideas desde las ET a las locales}

En los niveles local y nacional, los actores públicos y privados pueden buscar promover la difusión de ideas desde las ET, más allá de lo que puede ocurrir sin esa intervención (por ejemplo, Humphrey y Schmitz, 2001; Dussel Peters et al., 2003).

Como se refiere en la literatura sobre los clusters, un primer objetivo es el incremento de las capacidades y de la especialización territorial por medio del reforzamiento de la infraestructura, del sistema de educación, formación e investigación, así como de mecanismos de certificación. En el nivel local, la constitución de coaliciones con los principa-

\section{Desarrollo}


les actores privados y públicos para definir las prioridades del desarrollo, aprovechar las complementariedades y coordinar los esfuerzos es presentada como elemento esencial. Estos aspectos permiten en los territorios un desarrollo endógeno de mecanismos institucionales formales e informales de circulación de la información y de aptitud para aprovechar las oportunidades.

La movilización de recursos financieros y, en particular, la toma de medidas para garantizar el acceso al crédito de los proveedores de las ET es una condición para que las empresas puedan aprovechar los nuevos conocimientos derivados de la proximidad con las ET para invertir y desarrollar nuevas competencias productivas.

Sin embargo, estas acciones son limitadas en los países en desarrollo por la estructura — casi-jerarquía - de numerosas cadenas de valor global que pueden producir una dinámica de crecimiento empobrecedor (Kaplinsky, 2000), así como la existencia de barreras a la entrada que limitan las posibilidades de upgrading (Humphrey y Schmitz, 2001).

Los objetivos de la política macroeconómica son, también, factores que influyen en las capacidades de las empresas locales y determinan el aprovechamiento de las posibilidades de difusión de ideas desde las ET. Un régimen monetario restrictivo (altas tasas de interés, penuria de créditos) o un nivel insuficiente de demanda agregada — variable que depende, en gran medida, de la forma de relación salarial y de los presupuestos públicosvan a limitar las capacidades de las empresas locales para invertir y aprovechar las oportunidades para apropiarse las nuevas ideas. Sin embargo, una política macroeconómica expansionista en la mayoría de los países en desarrollo necesitaría regular de nuevo los flujos de capital y una acción supranacional para superar los riesgos de desequilibro de la balanza de cuenta corriente (Crotty, Epstein y Kelly, 1998).

\section{Limitar los obstáculos a la difusión de ideas y los riesgos de dinámicas perversas}

Con incentivos o medidas coercitivas, las autoridades públicas pueden influir sobre las ET para que limiten los obstáculos a la difusión de ideas y los riesgos de dinámicas perversas.

Hasta los ochenta, en la mayoría de los países en desarrollo, la ley permitió una selección soberana de la IED por parte de los gobiernos, de tal forma que fuera orientada a sectores y regiones específicas según los objetivos del proyecto de desarrollo nacional (para el caso de México, véase Dussel Peters, 2000). Aunque fueron desmantelados con la liberalización en las dos últimas décadas en muchos países, estos instrumentos permiten proteger a las empresas nacionales de la competencia internacional y, conforme al viejo argumento de List (1841), favorecen el desarrollo de las industrias nacientes. Al mismo tiempo, se puede abrir la nación a la IED en los sectores estratégicos y donde no hay esperanza de constitución de un aparato productivo nacional a corto o mediano plazo.

Los gobiernos locales o nacionales podrían condicionar la aceptación de la IED al cumplimiento de requerimientos en términos de transferencia de tecnologías (Chang, 1998) o

\section{Désaarrollo}


de contenido local de la producción (Qiu y Tao, 2001). En este caso, la existencia de mecanismos de control y de una situación de fuerza bastante favorable al gobierno del país receptor deben garantizar que las ET cumplan sus obligaciones. En caso contrario, éstas van a aprovechar la carencia de credibilidad de estas normas (por ejemplo, Barclay, 2003).

Uno de los principales obstáculos para que los gobiernos de los países receptores tengan el control selectivo de la IED o para la especificación de las condiciones que deben cumplir las ET son las exigencias de liberalización proveniente de instituciones internacionales como el FMI, así como de los acuerdos bilaterales o regionales que prohíben condicionar la inversión extranjera, por lo que algunos autores sugieren una moratoria sobre estos acuerdos (Crotty, Epstein y Kelly, 1998). Ante estas dificultades relacionadas con el ambiente internacional y los riesgos de boicot por parte de los inversionistas, los gobiernos pueden no aplicar los derechos de propiedad intelectual para incrementar las posibilidades de imitación.

En la situación de actual competencia entre los países para atraer la IED, muchos gobiernos no solamente la han liberalizado, sino también usan incentivos que benefician exclusivamente a las empresas extranjeras, muchas veces de manera indiscriminada. La literatura especializada coincide en que estas medidas suelen no ser eficientes para incrementar el bienestar nacional. Sin embargo, ante la ausencia de un acuerdo internacional que prohíba la competencia fiscal improductiva entre las naciones, los gobiernos temen un boicot por parte de los inversionistas externos. En consecuencia, se sugiere, por un lado, evitar la discriminación hacia las empresas locales y, por otro, focalizar estos incentivos en los sectores en los cuales pueda ocurrir la difusión de conocimientos y la transferencia de tecnologías (Blomström y Kokko, 2003; Mortimore y Vergara, 2003; UNCTAD, 2003).

Finalmente, los gobiernos locales y nacionales deben preocuparse por los efectos negativos de los comportamientos renteros de las transnacionales y su posición anticompetitiva, de mecanismos de evasión fiscal, así como de su influencia excesiva sobre el proceso de toma de decisión (UNCTAD, 2003). La promoción de organismos de regulación está sugerida para impedir o limitar la captación de rentas y garantizar la calidad de la producción en los casos donde las ET invierten en sectores muy concentrados, en particular en lo que concierne a servicios y monopolios públicos privatizados o recursos naturales. No osbtante, la situación de captura de los gobiernos frente a las ET, la debilidad de su poder de negociación en muchos países pobres y las características de los contratos iniciales, a veces establecidos en un contexto de fuerte corrupción, hacen que estos marcos de regulación no sean verdaderas garantías contra el oportunismo rentero de las ET. Frente a estos problemas, las expropiaciones pueden ser una opción, aunque sea clara su disminución desde los setenta y, además, muchas naciones se han comprometido a no tomar tales decisiones (Minor, 1994). Estas medidas solamente pueden producir ventajas si en el país existen las competencias para usar este aparato productivo. Se deben considerar también los costos,

\section{DeSarrollo}


en términos de degradación de las relaciones con los países de origen de las ET expropiadas y de los inversionistas.

El Cuadro 3 propone una síntesis de esta discusión. Frente a las condiciones necesarias para la generación de externalidades positivas, se presentan los obstáculos, las posibilidades de acción institucional de las instancias de gobernanza local y nacional, así como las limitantes intrínsecas o relacionadas con el contexto supranacional de estas herramientas de acción meso y macroinstitucional para influir en el impacto de la IED como fuente de ideas.

Conforme con lo que sugieren los desarrollos conceptuales acerca del papel de las instituciones en el proceso de crecimiento, existen diferentes herramientas que los gobiernos locales y nacionales pueden emplear para incrementar la generación de externalidades positivas de la IED y limitar las dinámicas perversas. Por un lado, se pueden fortalecer las capacitaciones de los territorios para absorber nuevas ideas. El incremento de la dotación de los territorios (educación e infraestructura, entre otros), la emergencia de buenos marcos de coordinación y de circulación de la información interempresas, así como la movilización de recursos y de sinergias para favorecer la especialización son elementos clave en la literatura sobre los clusters. La acción macroeconómica también puede influir en la posibilidad de las empresas locales de invertir para aprovechar las potencialidades de la llegada de nuevas ideas. Por otro lado, los gobiernos pueden tomar medidas obligatorias o incentivos para seleccionar la IED más conveniente para el desarrollo local y nacional.

Sin embargo, las instancias de gobernanza locales y nacionales disponen de márgenes de acción bastante débiles. En primer lugar, la gobernanza privada global de las cadenas de valor no tiene una verdadera contraparte, una instancia de gobernanza pública global, lo que implica una forma de subordinación de los territorios receptores de la IED. Por esa razón, las políticas de capacitación de los territorios son insuficientes para garantizar que las empresas locales puedan aprovechar la presencia de las ET. Además, la liberalización del comercio y la circulación de capitales limitan las posibilidades de acción macroeconómica en favor de la inversión nacional, que podría facilitar la absorción local de las nuevas ideas. En segundo lugar, la asimetría entre las ET y los países en desarrollo está reforzada por la concurrencia para atraer la IED, que se traduce en una carrera hacia abajo en la cual se eliminan los instrumentos públicos de control de la IED. Las normas supranacionales en materia de inversión y la presión de las instituciones internacionales se suman a este proceso de debilitamiento de las capacidades del Estado para controlar la IED.

\section{Conclusiones}

En este documento hemos presentado los principales argumentos que propone la literatura especializada en lo que concierne a las correas de transmisión entre la IED como fuente de ideas, la productividad y el crecimiento de las economías en desarrollo. Esta discusión 
CÉDRIC DURAND

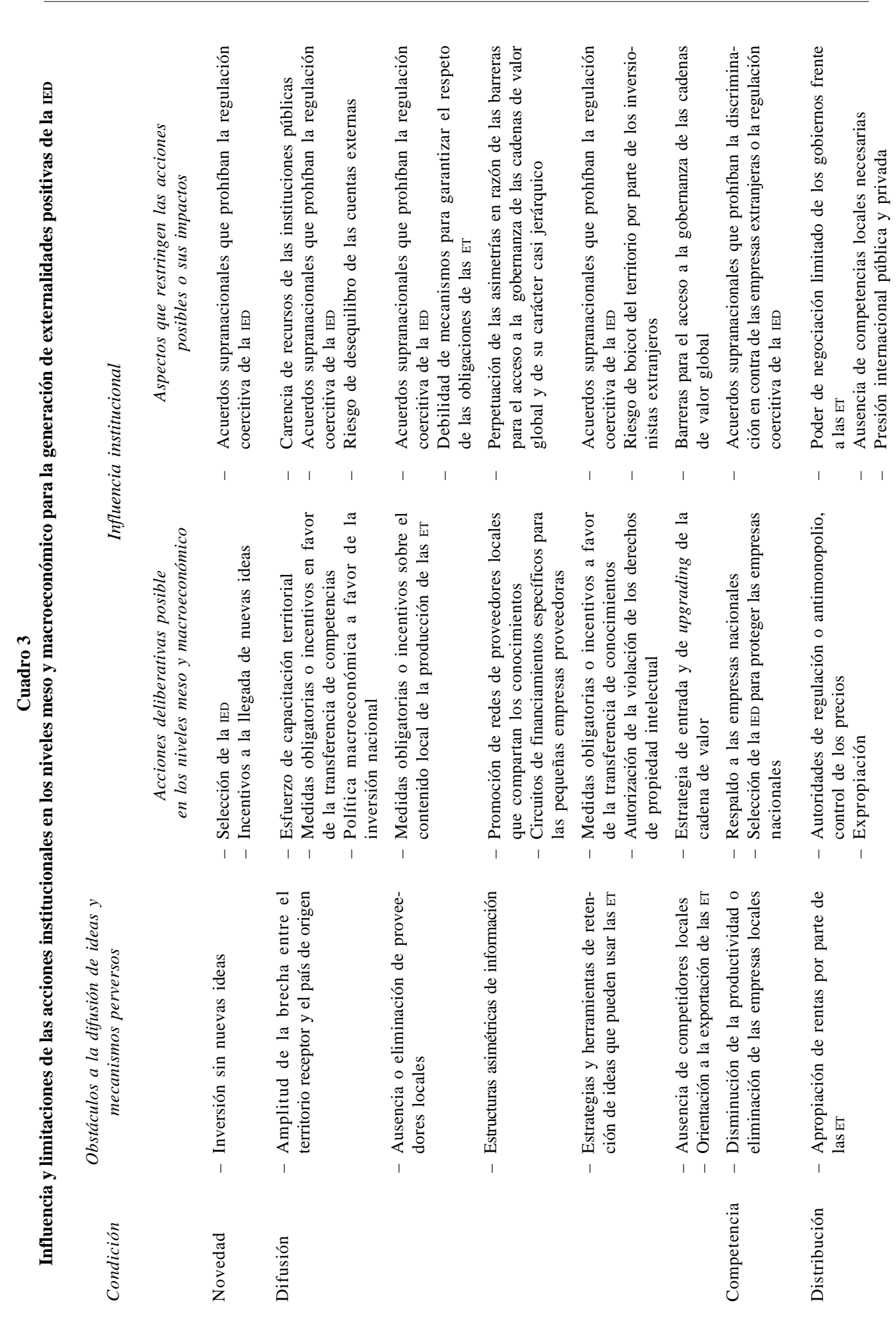

Deesaurrollo 
conceptual permite concluir la imposibilidad de suponer a priori un efecto neto positivo de la IED. Sus externalidades dependerán de las configuraciones sectoriales e institucionales.

La IED como fuente de ideas puede favorecer el crecimiento de la economía. Aprovechando las relaciones horizontales o verticales (hacia atrás o hacia adelante) con las ET, las locales pueden apropiarse de nuevas ideas, lo cual generaría un incremento de su productividad. Indirectamente, estas ganancias de productividad pueden aumentar la demanda agregada e inducir un proceso de profundización de la división del trabajo.

Esta relación virtuosa es, sin embargo, dependiente de lo novedoso de la IED, de las posibilidades de difusión de las citadas ideas productivas, del impacto de la competencia en las empresas locales, así como de la distribución de las ganancias eventuales de la productividad entre las ET y los agentes económicos locales. Hay menos posibilidades de generación de externalidades positivas en el nivel intraindustrial que en el marco de las relaciones verticales hacia atrás o hacia adelante. Por otra parte, hay que tomar en cuenta los costos de una eventual degradación acelerada del capital ecológico.

Estos factores impiden pronosticar, de manera descontextualizada, el efecto neto de la IED como fuente de ideas en la economía receptora. De hecho, existen obstáculos que no sólo pueden impedir o limitar la generación de externalidades positivas, sino producir una dinámica perversa de incremento de la brecha de ideas con el empobrecimiento del aparato productivo nacional del país receptor.

Para no quedarse en esta indeterminación del efecto neto de la IED, en nuestras hipótesis hemos resaltado la importancia de las configuraciones sectoriales e institucionales, haciendo énfasis en las características sectoriales y en las estrategias de las ET que influyen en el impacto de la IED. La construcción de configuraciones ideales-típicas muestra una gran heterogeneidad de posibilidades de difusión.

Esta heterogeneidad sectorial sugiere que la acción institucional en los niveles meso y macro no debe promover la IED de manera indiscriminada ni limitarse a la capacitación de los territorios, sino diferenciarse de acuerdo con las particularidades sectoriales y los objetivos del desarrollo nacional. Sin embargo, hay fuertes limitantes globales a las acciones meso y macroinstitucional. Por eso, desarrollar estrategias institucionales en el nivel global puede ser necesario para limitar los efectos negativos de la IED localmente y facilitar un proceso de aprendizaje de las empresas nacionales.

\section{Bibliografía}

Aglietta, M., "Avant-propos à la deuxième édition", en M. Aglietta, Régulation et crise du capitalisme, París, Odile Jacob, 1997.
Aitken, B.J. y A.E. Harrison, "Do Domestic Firms Benefit from Direct Foreign Investment? Evidence from Venezuela", en American 
Economic Review, Pittsburgh, vol. 89, núm. 3, 1999, pp. 605-618.

Amable, B. y P. Petit, "Identifying the Structure of Institutions to, Promote Innovation and Growth", en Couverture Orange, núm. 9919, París, CEPREMAP, 1999.

Ambrose, W.W., P.R. Hennemeyer y J.P. Chapon, "Privatizing Telecommunications Systems. Business Opportunities in Developing Countries", en International Finance Corporation Discussion Paper, núm. 10, Washington, World Bank, 1990.

Aoki, M., Information, Incentives and Bargaining in the Japanese Economy, Cambridge, Cambridge University Press, 1988.

Asad, S. y R. Balakrishnan, "Why do Firm Disintegrate? Toward an Understanding of the Firm Level Decision to Sub-Contract and its Impact on Labor", CEPA Working Paper, núm. 12, Nueva York, New School University, 2002.

Barclay, L.A., "FDI-facilitated Development: the Case of the Natural Gas Industry of Trinidad and Tobago", INTECH Discussion Paper Series, núm. 7, Tokyo, United Nations University, 2003.

Barro, R.J. y X. Sala-i-Martin, Economic Growth, Nueva York, McGraw-Hill, 1995.

Bellier, M. y Y.M. Zhou, "Private Participation in Infrastructure in China. Issues and Recommendations for the Road, Water and Power Sectors", en World Bank Working Paper, núm. 2, Washington, World Bank, 2003.

Blomström, M., "Foreign Investment and Productive Efficiency: the Case of Mexico", en The Journal of Industrial Economics, vol. 35, núm. 1, University of Essex, 1986, pp. 97-110.

Blomström, M. y A. Kokko, "Multinational Corporations and Spillover", en Journal of Economic Survey, vol. 12, núm. 2, Oxford, Blackwell, 1998, pp.1-31.

,"The Economics of Foreign Direct Investment Incentives", en Working Paper, núm. 168, Estocolmo, Stockholm School of Economics, 2003.

Blomström, M. y E.N. Wolff, "Multinational Corporations and Productivity Convergence in Mexico", en NBER Working Paper Series, núm. 3141, Cambridge, NBER, 1989.

Blomström, M. y F. Sjölom, "Technology Transfer and Spillovers: Does Local Participation Matter?", en European Economic Review, núm. 43, North Holland, Elsevier, 1999, p. 915-923.

Blomström, M. y H. Persson, "Foreign Investment and Spillover Efficiency in An Underdeveloped Economy: Evidence from Mexican Manufacturing Industry", en World Development, núm. 11, Montreal, Mc Gill University, 1983, pp. 493-550.

Bowles, S., "The Production Process in a Competitive Economy: Walrasian, Neo-Hobbessian and Marxian Models", en American Economic Review, núm. 75, Pittsburgh, AEA, 1985, pp. 16-36.
Cantwell, J., "A Survey of Theories of International Production", en C. Pitelis y R. Sudgen, The Nature of the Transnational Firm, Londres y Nueva York, Routledge, 2000, pp. 10-56.

Carcovic, M. y R. Levine, "Does Foreign Investment Accelerate Economic Growth?", Washington, World Bank, 2002, http://Www.worldbank.org/ research/conferences/financial_globalization/ fdi.pdf

Caves, R., Multinational Enterprise and Economic Analysis, Cambridge, Cambridge University Press, 1996.

CEPAL, La inversión extranjera en América Latina y el Caribe, Informe 2001, Santiago de Chile, Naciones Unidas, 2002.

— La inversión extranjera en América Latina y el Caribe, Informe 2002, Santiago de Chile, Naciones Unidas, 2003.

— L La inversión extranjera en América Latina y el Caribe, Informe 2003, Santiago de Chile, Naciones Unidas, 2004.

Chang, H.J., "Globalization, Transnational Corporation and Economic Development: Can Developing Countries Pursue Strategic Industrial Policy in a Globalizing World Economy?", en D. Baker, G. Epstein y R. Pollin, Globalization and Progressive Economic Policy, Cambridge, Cambridge University Press, 1998, pp. 97-113.

Chuang, Y.C. y C.M. Lin, "Foreign Direct Investment, R\&D, Spillover Efficiency: Evidence from Taiwan's Manufacturing Firms", en Journal of Development Studies, vol. 35, núm. 4, Londres y Nueva York, Routledge, 1999, pp. 117-137.

Collins, S.M. y B.P. Bosworth, "Economic Growth in East Asia: Accumulation versus Assimilation", en Brookings Papers on Economic Activity, vol. 96, núm. 2, Washington, The Brookings Institution, 1996, pp. 135-203.

Commons, J.R., Institutional Economics. Its Place in Political Economy, Nueva York, Macmillan, 1934.

Crotty, J.; G. Epstein y P. Kelly, "Multinational Corporations in the Neo-Liberal Regime", en D. Baker, G. Epstein y R. Pollin, Globalization and Progressive Economic Policy, Cambridge, Cambridge University Press, 1998, pp. 117-146.

Culem, C.G., "The Location Determinants of Direct Investment Among Industrialized Countries", en European Economic Review, vol. 32, núm. 4, North Holland, Elsevier, 1988, pp. 885-904.

De Mello, L.R., "Foreign Direct Investment in Developing Countries and Growth: a Selective Survey", en The Journal of Development Studies, vol. 34, ním. 1, Londres y Nueva York, Routledge, 1997, pp. 1-34.

Delapierre, C. y Milelli, Les firmes multinationales, París, Vuibert, 1995. 
Djankov, S. y B. Hoekman, "Foreign Direct Investment and Productivity Growth in Czech Enterprises", en World Bank Economic Review, vol. 14, núm. 1, World Bank, Washington, 2000, pp. 49-64.

Domar, E., "Capital Expansion, Rate of Growth and Employment", en Econometrica, núm. 14, The Econometric Society, Evanston, 1946, pp. 137-147.

Domar, E., Essays in the Theory of Economic Growth, Oxford, Oxford University Press, 1957.

Dugger, W.M., "Radical Institutionalism: Basic Concepts", en W.M. Dugger (editor), Radical Institutionalism: Contemporary Voices, Nueva York, Greenwood, 1989, pp. 1-20.

Dunning, J.H., Multinational Enterprises and the Global Economy, Wokimgham, Addison Welsey, 1993.

, "The Eclectic Paradigm of Production", en C. Pitelis y R. Sudgen, The Nature of The Transnational Firm, Londres y Nueva York, Routledge, 2000, pp. 119-139.

Durkheim, E., De la division du travail social, París, PUF, 1996.

Dussel Peters, E., "La subcontratación como proceso de aprendizaje: el caso de la electrónica en Jalisco", en G. Labarca (editor), Formación y empresa. El entrenamiento y la capacitación en el proceso de reestructuración global, Montevideo, GTZ/OIT/CEPAL, 1999, pp. 341-384.

, "La inversión extranjera en México", en Serie Desarrollo Productivo, núm. 80, Santiago de Chile, CePal, 2000, pp. 1-100.

Dussel Peters, E.; L. M. Galindo Paliza y E. Loría Díaz, Condiciones y efectos de la inversión extranjera directa y del proceso de integración regional en México durante los noventa, una perspectiva macro, meso y micro, México, Plaza y Valdés, UNAM, BID, INTAL, 2003.

Easterly, W., "The Ghost of Financial Gap: How the Harrod-Domar Growth Model Still Haunts Development Economics?", en Policy Research Working Papers, núm. 1807, Washington, World Bank, 1997.

Esser, K.; W. Hillebrand, D. Messner y J. MeyerStamer, Systemic Competitiveness. New Governance Patterns for Industrial Development, Londres, DIE, 1997.

Feenstra, R. y J.R. Markusen, "Accounting for Growth With New Inputs", en International Economic Review, núm. 35, Philadelphia, University of Pennsylvania, 1994, pp. 429-447.

Fuji Olechko, D., "Inversión extranjera y productividad en México", en Investigación Económica, vol. 63, núm. 248, México, Facultad de Economía, UNAM, 2004, pp. 147-173.

Gereffi, G. y M. Korzeniewicz (editores), Commodity Chains and Global Capitalism, Londres, Praeger, 1994.
Goldberg, L., "Financial-sector FDI and Host Countries: New and Old Lessons", en NBER Working Papers Series, núm. 10441, Cambridge, NBER, 2004.

Görg, H. y E. Strobl, "Multinational Companies and Productivity Spillovers: a Meta-analysis", en The Economic Journal, núm. 111, Oxford, Blackwell, 2001, pp. 723-739.

,"Multinational Companies and Indigenous Development: an Empirical Analysis", en European Economic Review, núm. 46, North Holland, Elsevier, 2002, pp. 1305-1322.

Griliches, Z., "Productivity, R\&D, and the Data Constraint", en American Economic Review, vol. 84, núm. 1, AEA, Pittsburgh, 1994, pp. 1-23.

Grossman, G.M. Y E. Helpman, Innovation and Growth in the Global Economy, Cambridge, MIT Press, 1991.

Hanson, G.H., "Should Countries Promote Foreign Direct Investment", en G24 Discussions Paper Series, núm. 9, Washington, G 24, 2001.

Hollingsworth, J.R. Y R. Boyer, "Coordination of Economic Actors and Social Systems of Production", en J.R. Hollingsworth y R. Boyer (editores), Contemporary Capitalism, the Embeddedness of Institutions, Cambridge, Cambridge University Press, 1997, pp. 1-47.

Hopkins, T.K. y I. Wallerstein, "CCs: Construct and Research", en G. Gereffi y M. Korzeniewicz (editores), Commodity Chains and Global Capitalism, Londres, Praeger, 1994, pp. 17-20.

Humphrey, J. y H. Schmitz, "Governance in Global Value Chains", en IDS Bulletin, vol. 32, núm. 3, Brighton, IDs, 2000, pp. 9-29.

Hymer, S.H., International Operations of National Firms: a Study of Foreign Direct Investment, Cambridge, MIT Press, 1976.

Intermón Oxfam, Repsol YPF en Bolivia, Oxford, Oxfam, mayo de 2004, http://Www.inter monoxfam.org/cms/HTML/catalan/1/dc150704 _Repsol_YPF_ok.pdf

Kaplinsky, R., "Globalisation and Unequalisation: What Can Be Learned from Value-chain Analysis?", en Journal of Development Studies, vol. 37, núm. 2, Routledge, Londres y Nueva York, 2000, pp. 117-146.

Kay, N., "The Ressource-based Approach to Multinational Enterprise", en C. Pitelis y R. Sudgen, The Nature of the Transnational Firm, Londres y Nueva York, Routledge, 2000, pp. 174-192.

Kinoshita, Y., "R\&D and Technology Spillovers Via FDI: Innovation and Absorptive Capacity", en Working Paper, núm. 349, Praga, CERGE-EL, 2000.

Kokko, A., "Technology, Market Characteristic and Spillovers", en Journal Development Economics, vol. 43, núm. 2, North Holland, Elsevier, 1994, pp. $279-293$.

\section{DeSarrollo}


Konings, J., "The Effect of Direct Foreign Investment on Domestic Firms: Evidence from Firm Level Panel Data in Emerging Economies", en Working Paper, núm. 344, Leuven, Licos-Center for Transition Economics, 2000.

Krugman, P.R. y M. Obstfeld, International Economics: Theory and Policy, Boston, Addison Wesley, 2000.

Kugler, M., "The Diffusion of Externalities From Foreign Direct Investment: Theory Ahead of Measurement", en Discussion Papers in Economics and Econometrics, Southampton, University of Southampton, 2000.

Kuznets, S., "Notes on the Takeoff", en W. W. Rostow (editor), The Economics of Takeoff Into SelfSustained Growth, Londres, McMillan, 1963.

List, F., Système national d'économie politique, París, Gallimard, 1998.

Markusen, J.R., "The Boundaries of Multinational Enterprises and the Theory of International Trade", en Journal of Economic Perspective, núm. 9, StPaul, 1995, pp. 169-189.

Markunsen, J.R. y A.J. Venables, "Multinational Firms and the New Trade Theory", en Journal of international economics, vol. 46, núm. 2, North Holland, Elsevier, 1998, pp. 183-203.

, "Foreign Direct Investment as a Catalyst for Industrial Development", en European Economic Review, vol. 43, núm. 2, North Holland, Elsevier, 1999, pp. 335-356.

Megginson, W.L. y J.M. Netter, "From State to Market: a Survey on Empirical Studies on Privatization", en Journal of Economic Literature, núm. 39, Pittsburgh, AEA, 2001, pp. 321-389.

Menger, C., Investigations into the Method of the Social Sciences with Special Reference to Economics, Nueva York, New York University Press, 1985.

Minor, M.S., "The Demise of Expropriation as an Instrument of LDC Policy, 1980-1992”, en Journal of International Business Studies, vol. 25, núm. 1, East Lansing, AIB, 1994, pp. 177-188.

Morán, T.H., Inversión extranjera directa y desarrollo, México, Oxford University Press, 2001.

- , Parental Supervision: the New Paradigm for Foreign Direct Investment and Development, Washington, Institute for International Economics, 2001.

Mortimore, M., "Corporate Strategies for FDI in the Context of Latin America's New Economic Model", en World Development, vol. 28, núm. 9, Montreal, Mc Gill University, 2000, pp. 1611-1626.

Mortimore, M. y S. Vergara, "Nuevas estrategias de empresas transnacionales. México en el contexto global”, en Dussel Peters et al., Condiciones y efectos de la inversión extranjera directa y del proceso de integración regional en México durante los noventa, una perspectiva macro, meso y micro, México, Plaza y Valdés, UNAM, BID, INTAL, 2003, pp. 91-133.

North, D.C., Institutions, Institutional Change and Economic Performance, Cambridge, Cambridge University Press, 1990.

, "Institutions and Economic Performance", en U Mäki; B. Gustafsson y C. Knudsen, Rationality, Institutions and Economic Methodology, Londres, Routledge, 1993.

O'sullivan, P.J., “An Assessment of Ireland's ExportLed Growth Strategy Via Foreign Direct Investment, 1960-1980", en Weltwirtschaftliches Archiv, núm. 129, Institut für Weltwirtschaft, Kiel, 1993, pp. 129-138.

Péres, W., Foreign Direct Investment and Industrial Development in Mexico, París, OCDE, 1990.

Petit, P., "Large Network Services and the Organisation of Contemporary Capitalism", en Couverture Orange, CEPREMAP, París, 2003.

Piore, M.J., "Nouvelles remarques sur les trajectoires technologiques", en R. Boyer y B. Chavance (editores), Les figures de l'irréversibilité en économie, París, Editions de l'EHEss, 1991, pp. 138-150.

Porter, M., "Clusters and the New Economics of Competition", en Harvard Business Review, Boston, Harvard Business School, noviembre de 1998, pp. 77-90.

Qiu, L.D. y Z. Tao, "Export, Foreign Investment and Local Content Requirement", en Journal of Development Economics, núm. 66, North Holland, Elsevier, 2001, pp. 101-125.

Ramírez, M.D., "Foreign Direct Investment in México: a cointegration analysis", en Journal of Development Studies, vol. 37, núm. 1, Routledge, Londres y Nueva York, 2000, pp. 138-162.

Rivera-Bátiz, F. y L. Rivera-Bátiz, "The Effects of Direct Foreign Investment in the Presence of Increasing Returns Due to Specialization", en Journal Development Economics, vol. 34, núm. 2, North Holland, Elsevier, 1990, pp. 287-307.

Rodrick, D.; A. Subramanian y F. Trebbi, "Institutions Rule: the Primacy of Institutions Over Geography and Integration in Economic Development", en NBER Working Paper Series, núm. 9305, Cambridge, 2002.

Rodríguez-Clare, A., "Multinationals, Linkages and Economic Development", en American Economic Review, vol. 86, núm. 4, Pittsburgh, AEA, 1996, pp. 852-873.

Romer, P., "Crazy Explanations for the Productivity Slowdown", en S. Fischer (editor), NBER Macroeconomics Annual, Cambridge, 1987, pp. 163-202.

, "Idea Gaps and Object Gaps in Economic Development”, en Journal of Monetary Economics, 
vol. 32, núm. 3, Simon Graduate School of Business, Rochester, 1993, pp. 543-574.

, "The Origins of Endogenous Growth", en Journal of Economic Perspectives, vol. 8, núm. 1, AEA, St. Paul, 1994, pp. 3-22.

Rostow, W.W., The Stages of Economic Growth. A Non Communist Manifesto, Cambridge, Cambridge University Press, 1960.

Ruiz Durán, C., Potencialidades de las entidades federativas para desarrollar núcleos de economía digital, México, Facultad de Economía, unAm, 2004.

Rutherford, M., Institutions in Economics, Cambridge, Cambridge University Press, 1994.

Sacchetti, S. y R. Sugden, "The Governance of Networks and Economic Power: the Nature and Impact of Subcontracting Relationships", en Journal of Economic Surveys, vol. 17, núm. 5, Blackwell, Oxford, 2003, pp. 669-691.

Sapir, J., Les trous noirs de la science économique, París, Albin Michel, 2000.

Schmitz, H. y P. Knorringa, "Learning from Global Buyers", en IDS Working Paper, núm. 100, IDS, Brighton, 1999.

Segerstrom, P.S., "Innovation, Imitation and Economic Growth", en Journal of Political Economy, núm. 99, University of Chicago, Chicago, 1991, pp. 807-827.

Smarzynska, B.K., "Does Foreign Investment Increase the Productivity of Domestic Firms? In Search of Spillovers Through Backward Linkages", en World Bank Policy Research Working Paper, núm. 2923, World Bank, Washington, 2002.

Solow, "A Contribution to the Theory of Economic Growth" en Quarterly Journal of Economics, núm. 70, Harvard University, Department of Economics, Boston, 1956, pp. 65-94.

Sweezy, P.M. y H. Magdoff, "Notas sobre la empresa multinacional”, en P.M. Sweezy et al., Teoría y práctica de la empresa multinacional, Buenos Aires, Periferia, 1974, pp. 11-43.

Teece, D.J., "Technology Transfer by Multinational Firms: the Resource Cost of Transferring Technological Know-how", en Economic Journal, vol. 87, núm. 346, Oxford, 1977, pp. 242-261.

UNCTAD, World Investment Report. Investment Trade and International Policy Agreement, Ginebra y Nueva York, United Nations, 1996.

, World Investment Report. Promoting Linkages, Nueva York y Ginebra, United Nations, 2001.

- World Investment Report. FDI Policies for Development, National and International Perspectives, Ginebra y Nueva York, United Nations, 2003a.

, "FDI and Development: Policy Issues Related to the Growth of FDI in Services", feedback from the UNCTAD Expert Meeting Held on 29-31 October 2003, 2003b.

Vanberg, V.J., Rules and Choice in Economics, Londres, Routledge, 1994.

Walliser, B., L'économie cognitive, París, Editions Odile Jacob, 2000.

Wolf, B.M., "Industrial Diversification and Internationalization: Some Empirical Evidence", en Journal of Industrial Economics, núm. 2, Universidad de Essex, 1977, pp. 177-191.

$\mathrm{Xu}, \mathrm{B} .$, "Multinational Enterprises, Technology Diffusion, and Host Country Productivity Growth", en Journal of Development Economics, núm. 62, Elsevier, North Holland, 2000, pp. 445-476. 